\title{
Spatial Analysis of Lettuce Downy Mildew Using Geostatistics and Geographic Information Systems
}

\author{
B. M. Wu, A. H. C. van Bruggen, K. V. Subbarao, and G. G. H. Pennings
}

First, second, and third authors: Department of Plant Pathology, University of California, Davis 95616; and fourth author: Origin Nederland B.V., Serviceline Baan, Baron van Nagellstraat 140, 3771 LL Barneveld, the Netherlands.

Current address of B. M. Wu: Department of Plant Pathology, University of California, Davis, U.S. Agricultural Research Station, 1636 East Alisal Street, Salinas 93905.

Current address of A. H. C. van Bruggen: Biological Farming Systems, Wageningen University and Research Centre, Marijikeweg 22, 6709 PG, the Netherlands.

Accepted for publication 29 October 2000.

\begin{abstract}
Wu, B. M., van Bruggen, A. H. C., Subbarao, K. V., and Pennings, G. G. H. 2001. Spatial analysis of lettuce downy mildew using geostatistics and geographic information systems. Phytopathology 91:134-142.

The epidemiology of lettuce downy mildew has been investigated extensively in coastal California. However, the spatial patterns of the disease and the distance that Bremia lactucae spores can be transported have not been determined. During 1995 to 1998, we conducted several field- and valley-scale surveys to determine spatial patterns of this disease in the Salinas valley. Geostatistical analyses of the survey data at both scales showed that the influence range of downy mildew incidence at one

A linear relationship was detected between semivariance and lag distance at the field scale, although no single statistical model could fit the semivariograms at the valley scale. Spatial interpolation by the inverse distance weighting method with a power of 2 resulted in plausible estimates of incidence throughout the valley. Cluster analysis in geographic information systems on the interpolated disease incidence from different dates demonstrated that the Salinas valley could be divided into two areas, north and south of Salinas City, with high and low disease pressure, respectively. Seasonal and spatial trends along the valley suggested that the distinction between the downy mildew conducive and nonconducive areas might be determined by environmental factors.
\end{abstract} location on incidence at other locations was between 80 and 3,000 m.
Spatial patterns of plant diseases over time can provide information on the importance of primary inoculum, mechanisms of pathogen dispersal, direction and distance of disease spread, and effects of environmental factors on disease epidemics. A number of spatial statistical techniques have been employed to characterize the distribution of plant pathogens and diseased plants. Methods such as indices of dispersion, variance-to-mean ratios, and frequency distributions do not consider the spatial location of sample sites or their relationship to nearby sites, and thus cannot detect spatial dependency among sample sites (11,27). Several other methods, such as two-dimensional distance class analysis (14), spatial and spatiotemporal autocorrelation analysis $(12,18)$, and spatiotemporal autoregressive integrative moving average techniques (5) have been used to address the spatial relationships among sample sites.

Geostatistical techniques, originally developed for use in mining (2), have also been applied in plant pathology to quantitatively characterize spatial patterns of disease or pathogen populations in space and over time $(7,9,15,25,33)$. These techniques take into consideration both the random and systematic characteristics of spatially distributed variables. Besides being able to detect spatial dependency, geostatistical techniques can be used for continuous and discrete variables, and require less stringent assumptions of stationarity compared with spatial autocorrelation techniques. Spatial dependence can be analyzed (directionally or omnidirectionally) with semivariograms, which quantify spatial dependence by measuring the variation between samples, separated by a sepa-

Corresponding author: B. M. Wu; E-mail address: bmwu@ucdavis.edu

Publication no. P-2000-1206-01R

(c) 2001 The American Phytopathological Society ration vector, the "lag distance." Making use of the spatial dependency characteristics, kriging and cokriging can also be used to estimate sample values at sites not sampled. These procedures are usually carried out in a geographic information system (GIS).

GIS is an important tool for understanding and managing the environment. GIS techniques have been widely used in the fields of land planning, management of natural resource, landscape ecology, transportation, and pollution spread. More recently, GIS has emerged as a new tool in insect and disease management (13). GIS allows us to make connections between characteristics based on geographic proximity. These connections are often unrecognized without GIS, but can be vital to the understanding and management of activities and resources.

It is also theoretically possible to incorporate disease-forecasting models into a GIS if the cost and time are not constraints. Because high-resolution weather forecast data are available, pest or disease development can be predicted based on their dependency on some critical weather variables and the geographic distribution of inoculum in a GIS framework. Examples include temperaturebased prediction of development of gypsy moth (Lymantria dispar) (19), and risk assessment for virus infection based on the prevalence of diseased crop and weed hosts, and insect vectors (13). Although the cost and knowledge requirements for establishing a GIS are high, it may be cost effective for management of some complex diseases that may spread over large geographic areas and cause substantial losses in yield and revenues.

Production of lettuce (Lactuca sativa L.) in the United States is concentrated in California and Arizona. In California, lettuce is mainly grown in coastal areas of the Salinas and Santa Maria valleys through most of the year. Due to the cool weather and highly intensive lettuce production systems, downy mildew (caused by Bremia lactucae Regel) causes considerable losses in commercial production in these valleys (17). 
Lettuce downy mildew occurs every growing season in coastal California. The exact sources of primary inoculum are unknown. Soilborne oospores are one possible but unconfirmed source of primary inoculum (23). Cultivated lettuce in other parts of California or Arizona, and wild Lactuca spp. (8) could be other sources of primary inoculum. For development of a disease warning system for downy mildew control in coastal California, it was assumed that inoculum would always be available (20).

Asexual spores (sporangia) are the only means of subsequent disease spread. Sporangia are disseminated by wind and water splash, but the relative importance of these factors is unknown. Yet, the mechanism of dissemination determines the distribution of disease in the field. Dissemination by water splash generally results in short distance transport and steep disease gradients. Madden (10) found that incidence of strawberry anthracnose generally declined to almost 0 at $2 \mathrm{~m}$ from the inoculum source. In contrast, wind dissemination can result in long-distance dispersal and shallow disease gradients with long tails. Dissemination by wind may itself operate through two different mechanisms (29), the first resulting in steep gradients within foci, the second in the establishment of daughter foci along shallow gradients, the socalled dual dispersal phenomenon. Aylor (1) attributed this phenomenon to some spores getting transported within the canopy and some escaping the canopy into the more freely moving air above the canopy for long-distance dissemination. The distance that sporangia of B. lactucae can travel has not been determined. However, sporangia of Peronospora tabacina, a closely related pathogen, are carried over hundreds or even thousands of kilometers from south central Texas to North Carolina and further north (4). Thus, it is generally assumed that sporangia of other downy mildew pathogens can also be carried over long distances by wind (3).

The only report on the spatial distribution of downy mildew in the Salinas valley was published more than 30 years ago (24). In that study, the Salinas valley was divided into three zones from the northwestern portion to the southeastern end of the valley, a northern zone where only downy mildew was found, a middle zone where both downy mildew and powdery mildew occurred, and a southern zone where no downy mildew developed. Over the past three decades, the pathogen and host populations and the production systems in the Salinas valley have changed signifi- cantly. A more detailed quantitative analysis of the spatial distribution of the disease is necessary for improvement of our understanding of this disease.

This study was carried out as a part of our research to develop a regional forecasting system for lettuce downy mildew (20). The specific objectives of this study were (i) to describe the distribution of lettuce downy mildew in space and over time in the Salinas valley; (ii) to determine the range of influence of disease incidence at one location on incidence at other locations; and (iii) to identify regions with different downy mildew risks within the valley using GIS. Preliminary reports of this research have been published previously $(28,32)$.

\section{MATERIALS AND METHODS}

Study area. Because the Salinas valley is the most important lettuce production area in the United States, all of our studies were conducted in this valley. The Salinas valley is located along the central coast of California (Fig. 1A). The study area covered approximately $100 \mathrm{~km}$ in length and an average of $10 \mathrm{~km}$ in width. The northern opening of the valley is wide and begins in Monterey Bay (Fig. 1B). The valley narrows as it approaches south and ends south of King City. The area lies mostly at elevations $<100 \mathrm{~m}$ above sea level and is generally characterized by intensively cultivated soils covered with cool-season vegetable crops and strawberries.

Disease assessment on the valley scale. Six surveys were conducted in the Salinas valley and Watsonville area monthly from April to September 1995. During each survey, 32 to 55 fields were arbitrarily selected throughout the regions, regardless of the age of the plants. In each field, plants were sampled in a "V" pattern by two persons starting from the two corners on one side of the field and meeting at the middle on the other side of the field. One plant was sampled every 1 to $4 \mathrm{~m}$ depending on the size of the field so that each person sampled 50 plants per field. The number of lettuce plants showing downy mildew symptoms (sporulation) was counted, and incidence per field was calculated by combining the results of two persons. Longitude and latitude were measured with a global positioning system (Magellan System Corp., San Dimas, CA) to locate individual fields. The growth stage of the lettuce
A

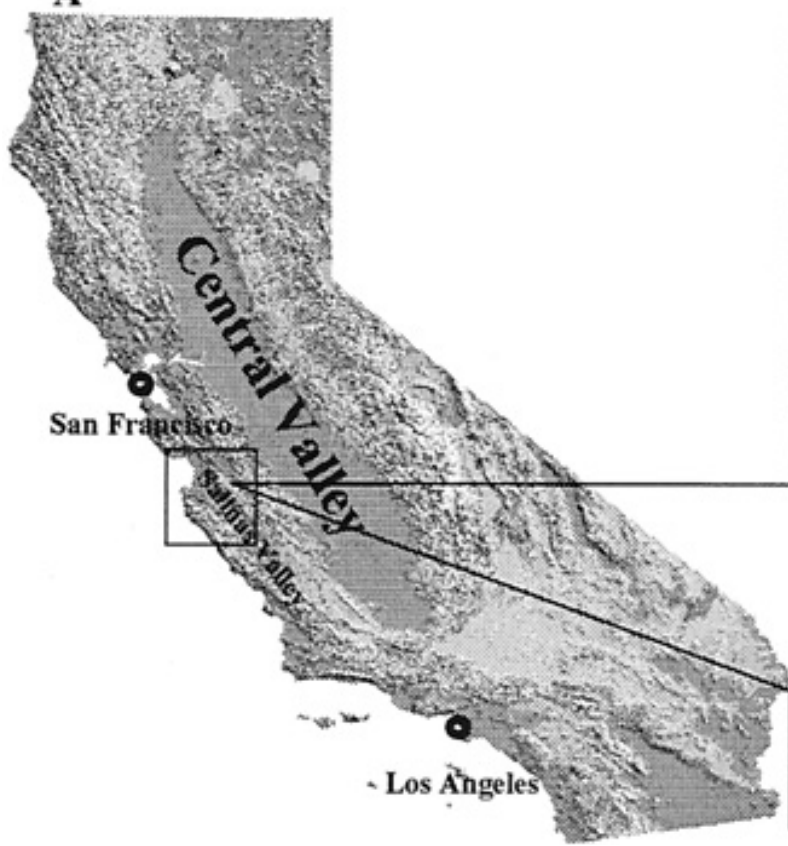

B

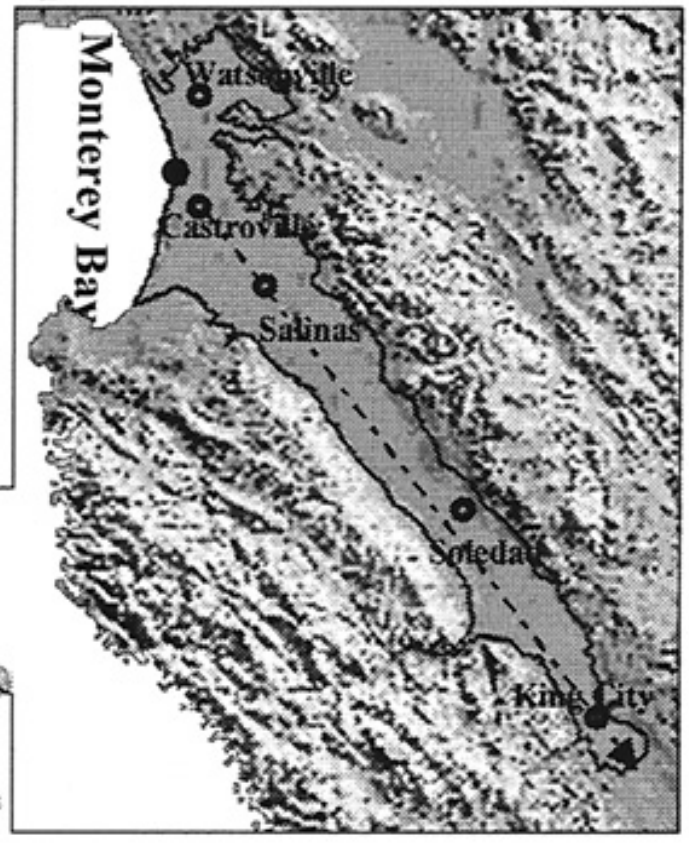

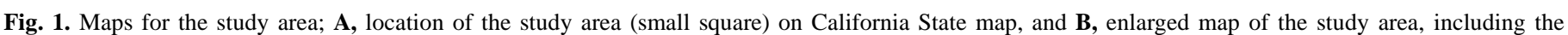
Watsonville area and the Salinas valley, with the 100-m elevation outlined (solid curve) and the central line of the valley marked (dashed line). 
crop and the type of lettuce (crisphead, Romaine, butterhead, or leaf lettuce) were also recorded for each field. In the summer of 1997, 50 to 71 fields were surveyed four times at weekly intervals. The same fields were sampled every week, except when access was forbidden due to recent pesticide application. On the first survey on 16 June, only fields with a lettuce crop at or before the nine-leaf stage were selected, so the lettuce would not have been harvested until 7 July. The surveys covered only the north and middle portions of the valley from Castroville to Soledad, where more lettuce fields could be found. The fields were selected so that they were distributed as evenly as possible across the surveyed area. Besides growth stage and lettuce type, the type of irrigation system was also recorded for each field.

Assessment of downy mildew within fields. One and three commercial lettuce fields were chosen for disease assessment in 1996 and 1998, respectively, near Salinas. In 1996, a $20 \times 15$ grid $(80 \times 150-\mathrm{m}$ sampling area) was sampled in a field with lettuce plants at 10-leaf stage. Two neighboring grid points were separated by $4 \mathrm{~m}$ across beds and $10 \mathrm{~m}$ along the beds. One sample site was located at each intersection of the grids. Each sample consisted of four lettuce plants (two plants in each of two rows per bed). In 1998, a $12 \times 12$ grid was sampled in three fields (one field with Romaine lettuce plants at 12-leaf stage, two fields with crisphead lettuce at stage prior to mature). Adjacent grids were separated by $20 \mathrm{~m}$ in both directions. Ten lettuce plants were examined at each site (five plants in each of two rows per bed). The number of lettuce plants showing downy mildew symptoms (sporulation) was recorded for each sample site.

Seasonal dynamics of downy mildew. To characterize the seasonal patterns of lettuce downy mildew in the Salinas valley
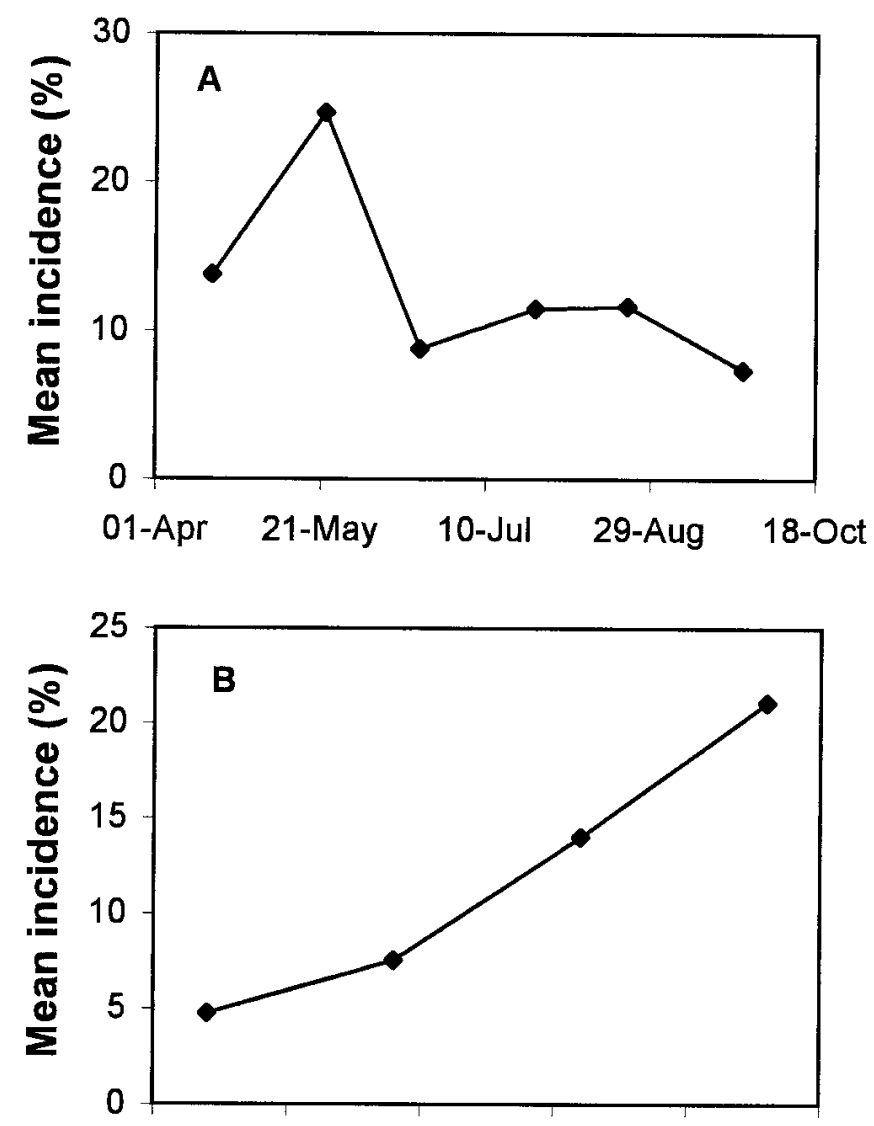

14-Jun 19-Jun 24-Jun 29-Jun 04-Jul 09-Jul Disease assessment date

Fig. 2. Seasonal changes in mean incidence of lettuce downy mildew (Bremia lactucae) in A, 1995, and B, 1997 surveys in the Salinas valley. and nearby areas, disease incidence data observed at different times in 1995 were analyzed with the general linear model (GLM) SAS (release 6.12, SAS Institute, Cary, NC) to test if seasonal changes were significant. Although disease incidence in the four surveys in 1997 might not reflect the seasonal changes of downy mildew because the surveys covered only a short period, the same analysis was also carried out on the disease incidence in 1997 surveys.

Geostatistical analysis of disease within fields. Semivariogram (also called variogram in some literature) analysis was performed on disease incidence and associated spatial locations $(x, y$ coordinates) using software "Variowin" (16). In this program, sample semivariogram values are generated based on semivariance $\left(\gamma_{h}\right)$ that is calculated from the differences in downy mildew incidence at points separated by a vector $h$ (distance $h$ at direction with an angle of $0^{\circ}, 45^{\circ}, 90^{\circ}$, and $135^{\circ}$ to the north):

$$
\gamma_{h}=\Sigma\left(I_{p}-I_{p+h}\right)^{2} / 2 N
$$

where $I_{p}$ and $I_{p+h}$ are the incidence at points $p$ and $p+h$, and $N$ is the total number of the point pairs separated by the vector $h$. To obtain a generalized view on semivariograms at field scale, we combined the semivariograms for the three 1998 surveys with the same sample pattern into a single semivariogram. We first standardized the disease data for each field with transformation

$$
T I_{p}=\left(I_{p}-\bar{I}_{i}\right) / \delta_{i}
$$

where $T I_{p}$ is incidence at point $p$ after transformation, $\delta_{f}$ and $\overline{I_{f}}$ are, respectively, the standard deviation and mean incidence per field. A combined semivariogram was generated from the transformed incidence data for all of the fields.

Geostatistical analysis at the valley scale. To conduct geostatistical analyses on the spatial patterns of lettuce downy mildew in the coastal regions, the latitude and longitude coordinates of the fields were first transformed into plane coordinates with a Universal Transverse Mercator (UTM) projection in ArcInfo (version 7.0, Environmental Systems Research Institute, Redlands, CA). The UTM coordinates of fields were used in the subsequent statistical analyses.

First, trends in disease incidence along the direction of the Salinas valley were examined. To calculate the distance from Monterey Bay to the sample, we rotated and shifted the $x$ and $y$ axes so the new $y$ axis (Fig. 1B, dashed line) went through the center of the valley from the northwestern end to the southeastern end of the valley. Then, regression analyses were conducted on the relationship between disease incidence and the distance from Monterey Bay along the direction of the valley. A polynomial model was used to fit the trend for each survey. The significance of each individual term (linear, quadratic, cubic, and higher terms) in the models was tested by the GLM procedure in SAS.

When a significant trend was found in a survey, the incidence data were detrended by subtracting the predicted disease value (based on the polynomial regression model) from the observed value. After detrending, the location data ( $x$ and $y$ coordinates), together with the associated disease incidence data (or residual if they were detrended) were input into Variowin to generate semivariograms for each survey. Nugget effects were estimated from the variance in the incidence data obtained by two persons for the same field. Considering the specific distribution pattern of the surveyed fields, only the directional semivariograms at the valleys direction were tested with omnidirectional semivariograms.

GIS analysis on spatial dynamics of downy mildew in the Salinas valley. A point coverage was generated from the $x, y$ coordinates of the fields for each survey in ArcInfo. Interpolations were carried out on the point coverages for all locations with an elevation $<100 \mathrm{~m}$ within the entire valley in 1995 and from Castroville to Soledad in 1997. Because none of the semivario- 
gram models (spherical, circular, exponential, Gaussian, or linear model) provided by ArcInfo fitted the semivariogram curves (maybe due to local trends or drifts in disease incidence), two universal methods (that approximate local drifts with a first-order and a second-order polynomial model, respectively) were used to generate interpolated lattices (radius $20 \mathrm{~km}$, minimal point number 15, and resolution $200 \mathrm{~m}$ ), and the variances of interpolation were examined. The inverse distance weighting (IDW) methods (search radius of $20 \mathrm{~km}$, minimal point number 15, and powers 1 , 2,3 , or 4) were compared with the kriging methods. After examining the interpolated results by different methods, we selected the IDW method with a power of 2 to generate an interpolated incidence grid (cell-based geographic data set) for each survey for subsequent analyses. After interpolation, nonagricultural lands were deleted by overlaying resulting grids with a land-use grid derived from land-use data for Monterey County downloaded from the U.S. geographical survey website, and the resulting grids were smoothened using the FOCALMEAN function in Grid (Grid is a raster or cell-based geoprocessing toolbox that is integrated with ArcInfo) with a moving window of $10 \times 10$ cells.

To give equal weight to the incidence data in each survey, all grids based on different surveys were standardized so that all of them had a mean of 0 and a standard deviation of 1 before conducting cluster analysis. Naturally occurring clusters of disease incidence levels were identified in Grid for the survey data of 1995, 1997, and the combined data set by using the ISOCLUSTER function in Grid. The separability of the clusters was examined for each survey date. The statistical distribution data generated by the ISOCLUSTER function for the clusters were used to check the overlaps between clusters by drawing an ellipse (the smallest ellipse centering on the mean vector for a cluster that encloses $95 \%$ cells in the cluster) around each of the clusters. Finally, each cell in the study area was assigned to a cluster, and the probability of this assignment was examined.
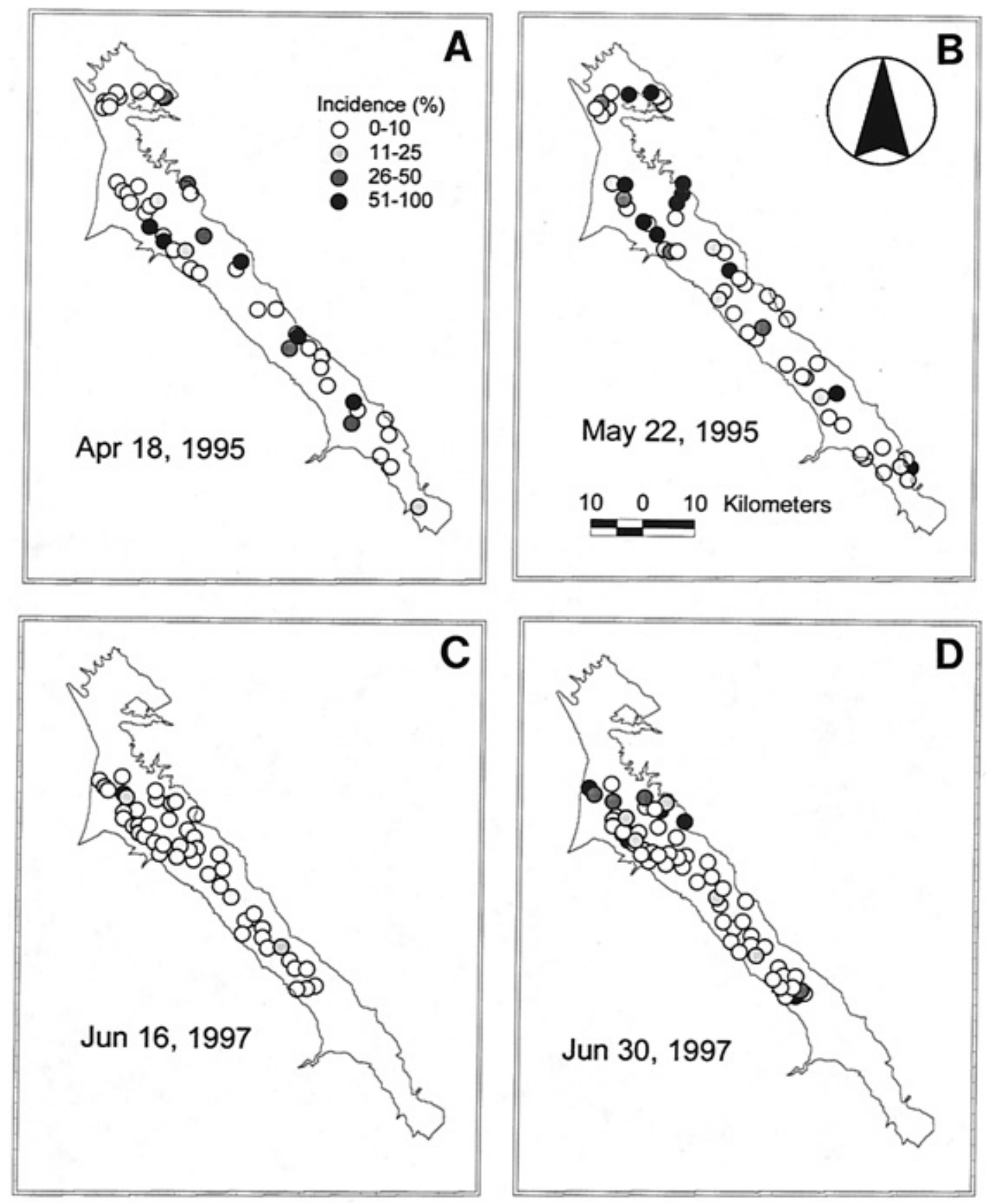

Fig. 3. Distribution of sample fields and observed incidence of lettuce downy mildew (Bremia lactucae) during A and B, the first two surveys in 1995 and $\mathbf{C}$ and D, the first and third weekly surveys in 1997. 


\section{RESULTS}

Disease dynamics over seasons. In 1995, incidence of lettuce downy mildew increased from early spring (April) and reached a peak in late spring (May). Then disease incidence decreased and remained at a relatively low level through the summer and fall (Fig. 2A). However, disease level consistently increased with time within the 1-month survey period in 1997 (Fig. 2B). A significant positive correlation was detected between growth stage of host and downy mildew incidence for both 1995 and 1997 (data not shown).

Disease incidence trend along the valley. Distribution of sample sites and observed disease incidence for two surveys each in 1995 and 1997 are depicted in Figure 3. In most of the surveys, lettuce downy mildew was observed in both Watsonville and the Salinas valley, even at the southeastern end of the Salinas valley. Within the Salinas valley, lettuce downy mildew was generally more severe near Monterey Bay than in the southern part of the valley. The decreasing trend in disease incidence from the northwestern to the southeastern part of the valley varied with surveys. Regression analysis detected significant trends along the direction of the valley for all of the 1997 surveys but not for the surveys in 1995. Second order polynomial models could be fitted to the trends of decreasing incidence with increasing distance from Monterey Bay although the coefficients of determination were generally low. The regression coefficient $\left(R^{2}\right)$ of the regression model was 0.21 for the survey on 30 June (Fig. 4), whereas it was 0.20, 0.33 , and 0.23 for surveys on 16 June $\left(I=0.151+0.00011 D^{2}-\right.$ $0.00825 D ; P=0.0048), 23$ June $\left(I=0.382+0.00030 D^{2}-0.0227 D\right.$; $P<0.0001)$, and 7 July $\left(I=0.667+0.00040 D^{2}-0.0317 D ; P=\right.$ $0.0015)$, respectively. Near the bay, the average disease incidence was high and the variation was large. Away from the bay to the southeast, the disease level decreased quickly within the first $20 \mathrm{~km}$, but remained at a relatively constant level in this direction for an additional $20 \mathrm{~km}$. However, sometimes the disease level increased again toward the southeastern end of the valley. For

TABLE 1. Number of fields with different lettuce types in 1995 and 1997 surveys

\begin{tabular}{|c|c|c|c|c|}
\hline \multirow[b]{2}{*}{ Sample date } & \multirow[b]{2}{*}{ Sample area ${ }^{\mathrm{a}}$} & \multicolumn{3}{|c|}{ Lettuce type $^{b}$} \\
\hline & & $\mathrm{B}+\mathrm{H}$ & $\mathrm{L}+\mathrm{R}$ & $\mathrm{UN}$ \\
\hline Apr 1995 & North & 8 & 10 & 1 \\
\hline Apr 1995 & Middle & 5 & 5 & 0 \\
\hline Apr 1995 & South & 6 & 2 & 1 \\
\hline Apr 1995 & Watsonville & 4 & 6 & 0 \\
\hline May 1995 & North & 10 & 4 & 0 \\
\hline May 1995 & Middle & 8 & 7 & 3 \\
\hline May 1995 & South & 8 & 4 & 1 \\
\hline May 1995 & Watsonville & 8 & 2 & 0 \\
\hline Jun 1995 & North & 11 & 4 & 0 \\
\hline Jun 1995 & Middle & 6 & 7 & 0 \\
\hline Jun 1995 & South & 13 & 8 & 0 \\
\hline Jun 1995 & Watsonville & 4 & 1 & 0 \\
\hline Jul 1995 & North & 13 & 6 & 1 \\
\hline Jul 1995 & Middle & 5 & 9 & 0 \\
\hline Jul 1995 & South & 0 & 5 & 1 \\
\hline Jul 1995 & Watsonville & 10 & 0 & 0 \\
\hline Aug 1995 & North & 11 & 1 & 1 \\
\hline Aug 1995 & Middle & 3 & 8 & 2 \\
\hline Aug 1995 & South & 2 & 4 & 0 \\
\hline Sep 1995 & North & 10 & 2 & 0 \\
\hline Sep 1995 & Middle & 7 & 9 & 0 \\
\hline Sep 1995 & South & 6 & 6 & 0 \\
\hline Sep 1995 & Watsonville & 7 & 1 & 0 \\
\hline 1997 & North & 34 & 4 & 0 \\
\hline 1997 & Middle & 17 & 16 & 0 \\
\hline
\end{tabular}

${ }^{a}$ North, from Monterey Bay to the south of Salinas; Middle, from the south of Salinas to Soledad; South, from Soledad to the southern end of the valley; and Watsonville, the area surrounding Watsonville City.

${ }^{b} \mathrm{~B}=$ butterhead lettuce, $\mathrm{H}=$ crisphead, $\mathrm{L}=$ leaf lettuce, $\mathrm{R}=$ Romaine lettuce, and $\mathrm{UN}=$ undetermined. most times of the surveys, there were more fields with head (crisphead and butterhead) lettuce in the northern portion of the valley and Watsonville area, but more leaf lettuce fields (including Romaine) in the middle and southern portion of the valley (Table 1). Disease incidence on the different types of lettuce (data not shown) was not significantly different. Although downy mildew is greatly affected by the type of irrigation, irrigation data were not available for 1995 and differences in irrigation systems was minimal between the northern and the middle portions of the Salinas valley in 1997. The northern portion of the valley had 9 fields with furrow or surface drip and 28 fields with sprinkler irrigation, whereas the middle portion of the valley had 7 fields with furrow or surface drip and 24 fields with sprinkler irrigation.

Sample semivariogram within fields. The semivariograms varied from field to field (Fig. 5). In the survey conducted in 1996, when the disease level was very low (mean incidence $3.2 \%$ ), semivariance of disease incidence did not increase much as distance increased. In 1998 surveys, when the mean disease incidence was $31.5,60$, and $71 \%$, the semivariograms clearly showed the spatial dependency across the range of the sample area. Simulation analysis in Variowin suggested a range of 80 to $100 \mathrm{~m}$ for the fields with mean incidence of $60 \%$. There was no sill for fields with mean incidence of 31.5 and $71 \%$ within 200 m. Furthermore, when the data from the three fields with the same sample pattern were combined after standardization, the semivariance increased with distance within fields (data not shown). Because no difference was detected among different directional (at an angle of $0^{\circ}$, $45^{\circ}, 90^{\circ}$, and $135^{\circ}$ ) and omnidirectional semivariograms, the directional semivariograms are not presented.

Semivariograms at the valley scale and relationship of semivariance to incidence. Because a significant trend in disease incidence was only detected along the direction of the valley in 1997, semivariograms were generated from the original 1995 disease incidence (data not shown) and detrended 1997 data (Fig. $6 \mathrm{~A}$ and $\mathrm{B}$ ). Because the directional (along the valley direction) and omnidirectional semivariograms were very similar, only omnidirectional semivariograms are illustrated. All of the semivariograms at the valley scale had a range of $<3 \mathrm{~km}$. Furthermore, the higher the disease incidence, the higher the sill of the semivariogram. For example, disease levels increased from 5 to $21 \%$ as lettuce grew from 16 June to 7 July in 1997, and the sill levels of the semivariograms also increased from approximately 0.008 to 0.08 .

Incidence interpolations and their semivariograms. The universal kriging methods resulted in anomalous disease incidence

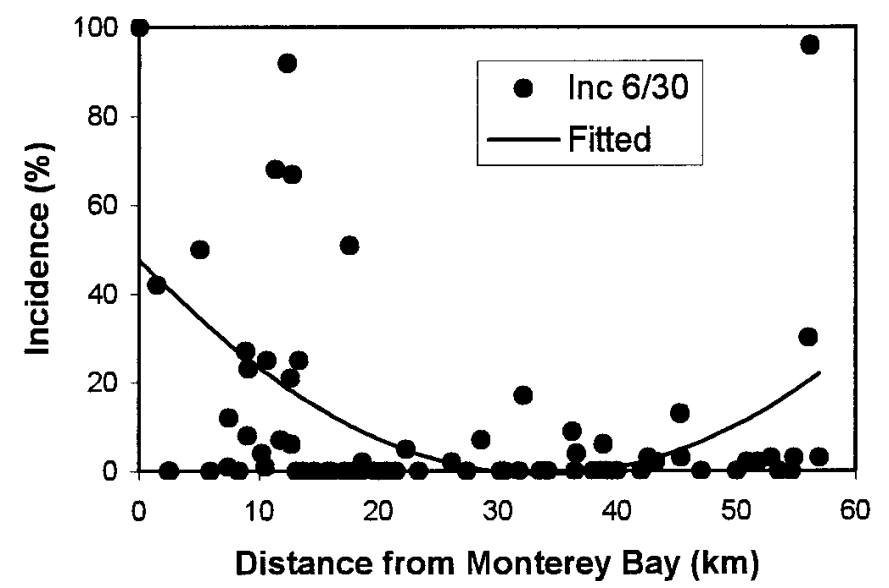

Fig. 4. The spatial trend of incidence of lettuce downy mildew (Bremia lactucae) in the survey on 30 June 1997. The distance was calculated along the central line of the Salinas valley beginning from the coastline of Monterey Bay. Observed data were represented by dots, and regression model by a line $\left(I=0.478+0.000425 D^{2}-0.0288 D ; R^{2}=0.21, P=0.001\right)$. 
estimates at some locations (values $<0 \%$ or $>100 \%$ ) because these methods extrapolated local trends (data not shown). Disease incidence interpolations by the IDW method with a power of 2 resulted in plausible incidence estimates throughout the valley. Maps of these interpolated data provide a view of lettuce downy mildew spread in space and over time in 1995 (Fig. 7A and B). In early spring, the epidemics of lettuce downy mildew might have started concurrently from various locations, showing several disease foci in the Salinas valley and one minor focus in Watsonville (Fig. 7A), which suggested that downy mildew pathogen might be able to overwinter at multiple sites in the valley. Later in the spring, lettuce downy mildew developed faster in the northern than in the southern part of the valley (Fig. 7B). The minor disease focus in Watsonville developed into a major disease focus, and the foci in the northern part of the valley spread out and merged into a large area while disease decreased in the central part and no significant progress occurred in the southern part (Fig. 7B). Subsequently, a considerable decrease in disease incidence occurred in all of the areas in early summer and no obvious change was detected later in summer. The disease levels were generally low through the whole valley.

Interpolation results for the surveys in 1997 (Fig. 7C and D) showed the disease development within a single cropping season. In early summer, a major disease focus was detected in the north of the valley, and a minor disease focus in the middle of the valley (Fig. 7C). A week later, the major focus in the north expanded, whereas the minor focus in the middle stopped developing. During the next 2 weeks, the foci in the north continued to develop into a large area, and incidence increased as well. Meanwhile, disease spread out into the southern part of the valley (Fig. 7D).

Cluster analyses. When cluster analysis was carried out with two clusters, a good separation was obtained for disease incidence on different dates in 1995 (Fig. 8A), 1997 (Fig. 8B), and for both years combined. The number of clusters could be increased, but the separability of the clusters decreased. The Salinas valley was primarily divided into two portions split around Salinas City, and this separation was highly consistent during the two different years (Fig. 8). The northern portion of the valley had much higher downy mildew incidence, whereas disease levels from Salinas southward were much lower except for a few small areas. As the probability that each cell was assigned into the cluster was compared (data not shown), for classifications with two clusters, more than $50 \%$ of the cells were assigned into a cluster with a confidence $\geq 90 \%$, and the percentages decreased when more clusters were used (data not shown).

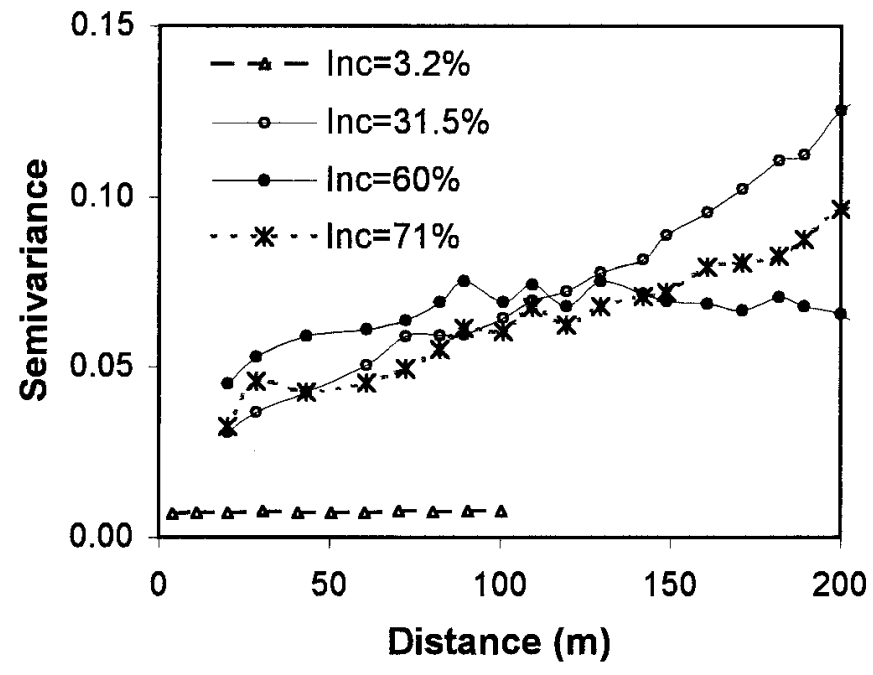

Fig. 5. Semivariograms of incidence of lettuce downy mildew (Bremia lactucae) in four lettuce fields with different incidence means in the Salinas valley.

\section{DISCUSSION}

This work is the first to our knowledge to provide a systematic quantitative analysis of the distribution of lettuce downy mildew in the Salinas valley since the qualitative analyses of the 1960s (24). From the analysis conducted in this study, the Salinas valley could be explicitly divided into two parts, north and south of Salinas City. More severe lettuce downy mildew occurred in the northern portion than in the central and southern portions of the valley. This could be explained by the climatic differences between the Monterey Bay area and the central and northern parts of the valley. The wet and cool weather near Monterey Bay provided the prolonged morning leaf wetness, cool morning and midday temperature, and high humidity, all of which contribute to optimal downy mildew development in laboratory, greenhouse, and field experiments $(3,17,21,22,24,26,30)$. The major difference between this study and the descriptive analyses of 1960s is that even in June and September, downy mildew was observed in this study near King City, $80 \mathrm{~km}$ south of Salinas. Factors such as the difference in weather or irrigation systems between the two study periods or genetic changes in the pathogen population may have caused the difference between the two periods. Although changes in pathotypes of the pathogen population have been well documented (6), changes in physiological characteristics besides pathogenicity have received little attention. To understand the long-term trends in downy mildew epidemics, it is necessary to investigate this aspect of population shifts in the future.

Lettuce tends to be more susceptible to downy mildew during spring and fall seasons owing to the weather and crop timing. The
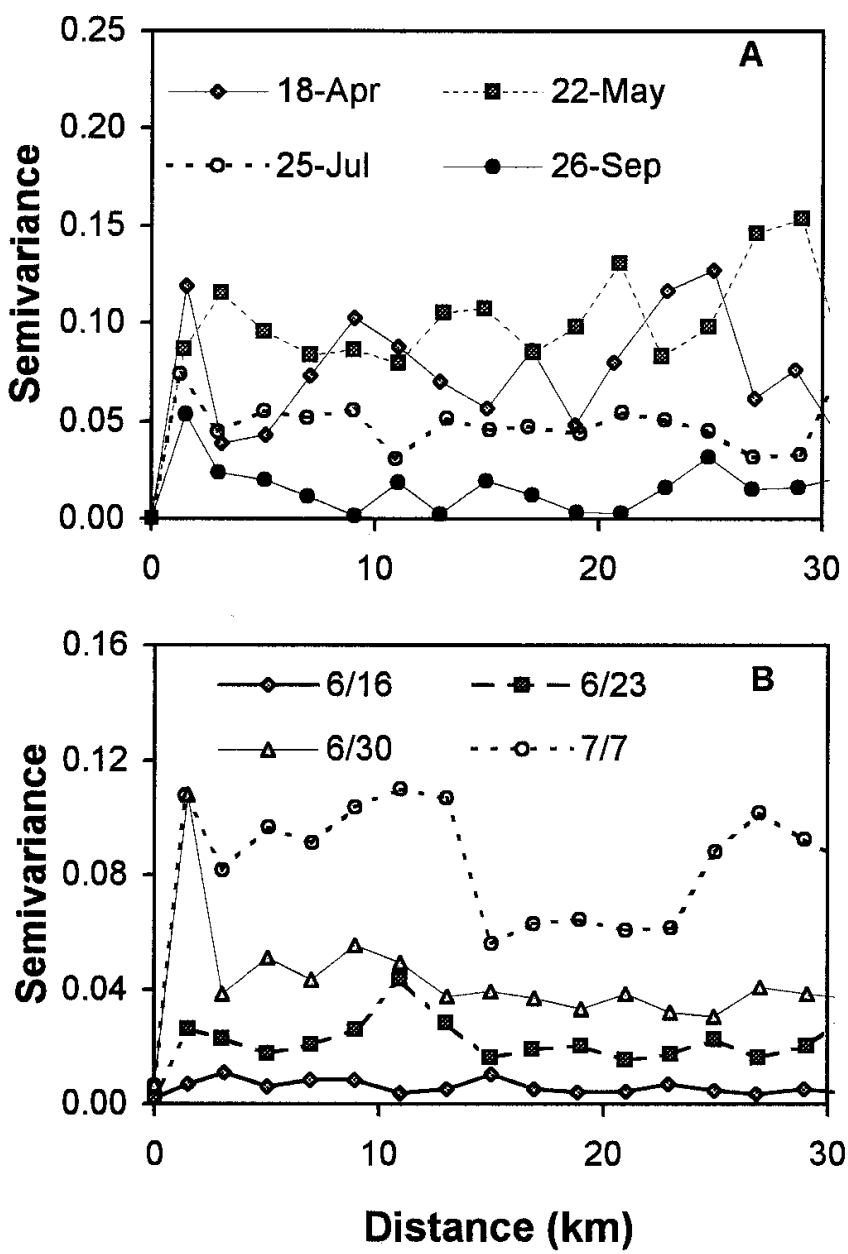

Fig. 6. Semivariograms for incidence of lettuce downy mildew (Bremia lactucae) at a scale covering the Salinas valley. The surveys were conducted on four different dates in A, 1995 and B, 1997. 

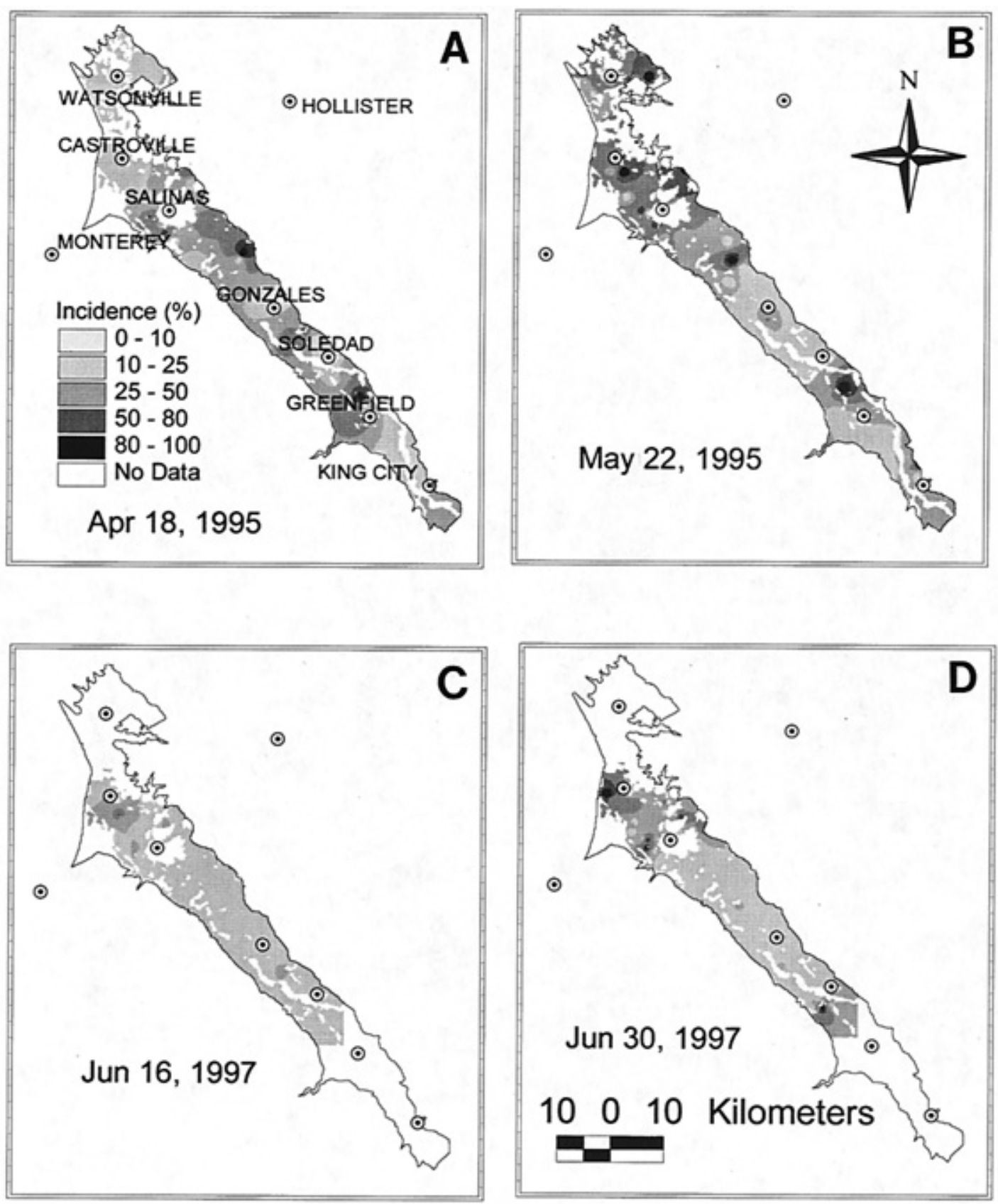

Fig. 7. Interpolation of incidence of lettuce downy mildew (Bremia lactucae) using inverse distance weighting method with a power of 2 in geographic information systems, showing the interpolated incidence for the surveys conducted on two dates in A and B, 1995 and C and D, 1997.

typical seasonal weather pattern in the Salinas valley is a cool and wet spring, followed by a warm and dry summer, and a cool but dry fall. Because lettuce downy mildew prefers cool temperatures, this seasonal weather pattern may have contributed to the seasonal pattern of the disease. However, another important factor may be the timing of crops. In commercial lettuce fields, downy mildew commonly appears only after thinning, and increases with lettuce growth subsequently. Incidence of downy mildew closely correlates to the growth stage of the lettuce crop. This perhaps partly explains why lettuce downy mildew increased from April to May, and decreased from May to June. Because the first major harvest usually starts after May in the valley, disease levels decreased after this major harvest when many of the heavily diseased lettuce plants were removed. The low downy mildew incidence through the summer and fall might be attributed to hot and dry weather during this period. To determine the relative contribution of weather and host age to the seasonal disease pattern, more detailed analyses are required.
At the field scale, semivariances tended to increase with distance between sample sites, varying among different fields, the semivariograms might have ranges approximately 80 to $100 \mathrm{~m}$, slightly longer than those calculated for cabbage downy mildew (25). Because semivariance increased monotonously up to more than $200 \mathrm{~m}$ for the combined data, and semivariograms reached a sill before $3 \mathrm{~km}$ at the valley scale, the influence range of downy mildew incidence was more likely to be located between 80 and $3,000 \mathrm{~m}$. The relatively short ranges are compatible with the results we obtained from UV-exposure experiments in growth chambers and sunlight-exposure experiments outdoors (31), in which the sporangia rarely survived for more than $4 \mathrm{~h}$ under normal temperature and solar radiation in the valley, indicating that the travel distance by the sporangia would be limited. The spread of lettuce downy mildew are affected by availability of inoculum, host age, and other environmental factors such as wind, humidity, leaf wetness, and solar radiation. Thus, another possible explanation for the different types of semivariograms at field and valley scales 

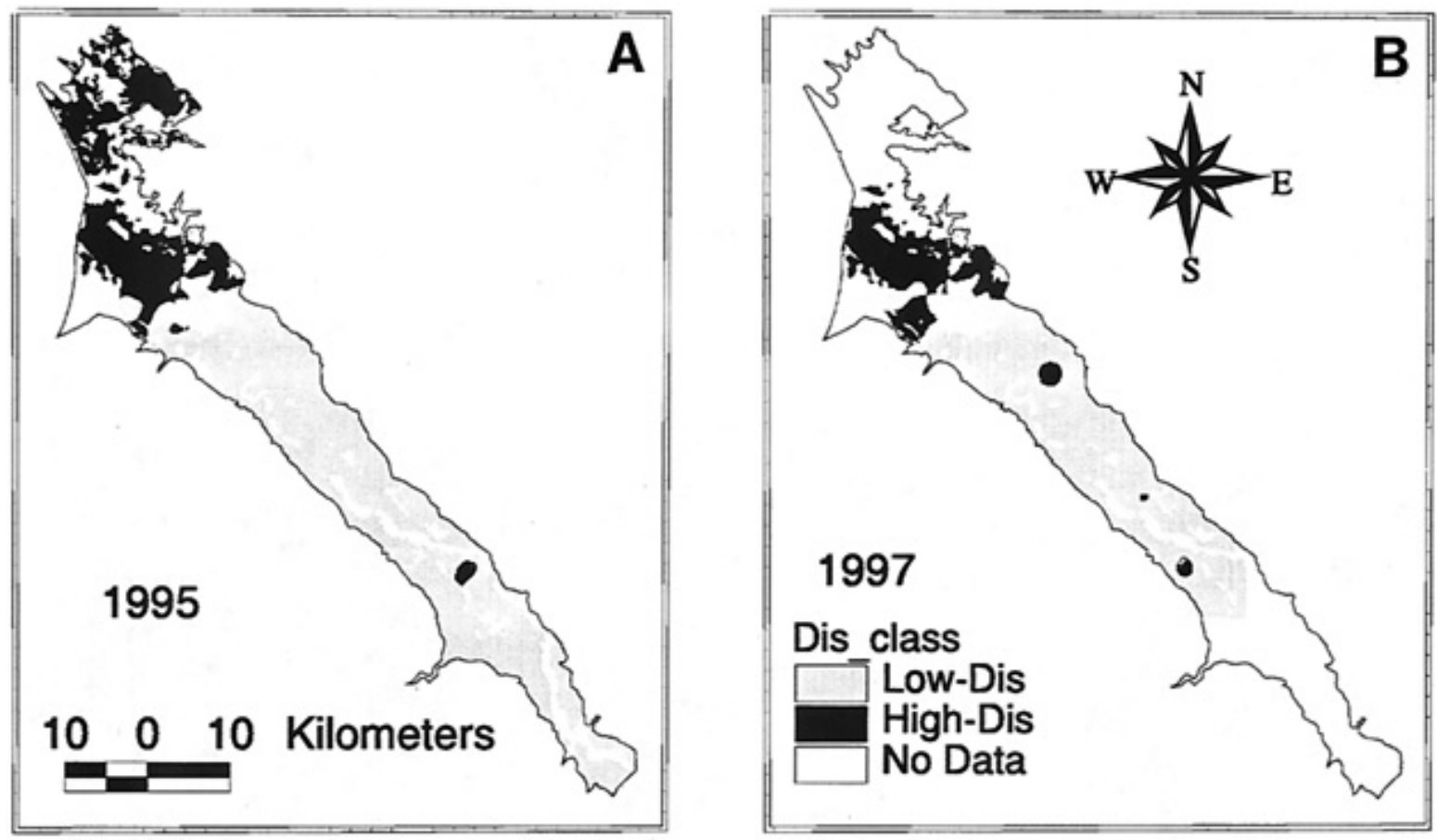

Fig. 8. The geographical distribution of two clusters with high and low incidence of lettuce downy mildew (Bremia lactucae) in the Salinas valley and Watsonville area. The cluster analyses were based on A, six monthly surveys in 1995 and B, four weekly surveys in 1997, respectively.

was that the difference in downy mildew incidence within a field was mainly because of inoculum availability, but the difference between fields was due more to environmental factors and host age. However, the exact distance of the influence range of lettuce downy mildew cannot be determined because the two semivariograms had very different sill levels. The number of plants per sample at field scale (4 or 10 plants) were much smaller than those at the valley scale (100 plants), thus incidence for samples within fields tended to have higher variation than incidence for samples in surveys across the valley. The relationship between semivariogram sill and the number of plants per sample is very similar to a well-known variance-volume relationship in geostatistics (2), (i.e., the higher the sample volume, the lower the semivariogram sill). Before this study, no information was available for the range within which downy mildew-infected lettuce plants can influence each other or the maximum distance that the sporangia can be disseminated. Thus, we designed a two-step method to cover a wide range of distances. We, however, were unable to combine the two surveys due to the difference in disease levels and the number of plants per sample. Because we now know the approximate range of influence, we believe that surveys covering an area of several fields with lettuce plants at approximately the same age and subject to the same agricultural practices, with distances ranging from tens to thousands of meters would yield a more precise estimate of the range of influence.

This study showed its great potential of GIS in spatial and epidemiological analysis of plant diseases. The interpolated disease maps illustrate the temporal-spatial spread of downy mildew in the Salinas valley. Furthermore, by using cluster analysis in GIS, we showed that there were two distinct regions in the Salinas valley, with respect to the epidemics of lettuce downy mildew: a conducive coastal region and a less conducive inland region. Further analyses are required to investigate how environmental factors contribute to the separation of these two clusters in the Salinas valley.

The relatively short influence range and the spatial pattern both suggested that the role of availability of inoculum in the epidemics of lettuce downy mildew is less important than environmental factors. The inoculum availability should not be a main variable for a warning system of lettuce downy mildew.

\section{ACKNOWLEDGMENTS}

This research was funded by grants from the California Lettuce Research Board and UC IPM to A. H. C van Bruggen, and U.S. Department of Agriculture National Research Initiatives grant 996-35313-3752 to A. H. C. van Bruggen, K. V. Subbarao, and R. W. Michelmore. We thank C. Moore who laid the groundwork for producing the GIS maps, S. T. Koike, O. Ochoa, and all the others who helped us with the disease surveys, and Y. Cao who organized and participated in the 1997 surveys.

\section{LITERATURE CITED}

1. Aylor, D. E. 1990. The role of intermittent wind in the dispersal of fungal pathogens. Annu. Rev. Phytopathol. 28:73-92.

2. Clark, I. 1979. Practical Geostatistics. Applied Science Publishers, London.

3. Crute, I. R., and Dixon, G. R. 1981. Downy mildew disease caused by the genus Bremia lactucae Regel. Pages 421-460 in: The Downy Mildews. D. M. Spencer, ed. Academic Press, New York.

4. Davis, J. M., and Main, C. E. 1986. Applying atmospheric trajectory analysis to problems in epidemiology. Plant Dis. 70:490-497.

5. Hudelson, B. E., Clayton, M. K., Smith, K. P., Rouse, D. I., and Upper, C. D. 1989. Nonrandom patterns of bacterial brown spot in snap bean row segments. Phytopathology 79:674-681.

6. Ilot, T. W., Durgan, M. E., and Michelmore, R. W. 1987. Genetics of virulence in California populations of Bremia lactucae (lettuce downy mildew). Phytopathology 77:1381-1386.

7. Larkin, R. P., Gumpertz, M. L., and Ristaino, J. B. 1995. Geostatistical analysis of Phytophthora epidemic development in commercial bell pepper fields. Phytopathology 85:191-203.

8. Lebeda, A., and Blok, I. 1990. Sexual compatibility types of Bremia lactucae isolates originating from Lactuca serriola. Neth. J. Plant Pathol. 96:51-54.

9. Lecoustre, R., Fargette, D., Fauquet, C., and de Reffye, P. 1989. Analysis and mapping of the spatial spread of African cassava mosaic virus using geostatistics and kriging techniques. Phytopathology 79:913-920.

10. Madden, L. V. 1997. Effects of rain on splash dispersal of fungal pathogens. Can. J. Plant Pathol. 19:225-230.

11. Madden, L. V., Hughes, G., and Ellis, M. A. 1995. Spatial heterogeneity of the incidence of grape downy mildew. Phytopathology 85:269-275.

12. Madden, L. V., Pirone, T. P., and Raccah, B. 1987. Analysis of spatial patterns of virus-diseased tobacco plants. Phytopathology 77:1409-1417.

13. Nelson, M. R., Felix-Gastelum, R., Orum, T. V., Stowell, L. J., and Myers, D. E. 1994. Geographic information systems and geostatistics in the design and validation of regional plant virus management programs. 
Phytopathology 84:898-905.

14. Nelson, S. C., Marsh, P. L., and Campbell, C. L. 1992. 2D-Class, a twodimensional distance class analysis software for the personal computer. Plant Dis. 76:427-432.

15. Orum, T. V., Bigelow, D. M., Cotty, P. J., and Nelson, M. R. 1999. Using predictions based on geostatistics to monitor trends in Aspergillus flavus strain composition. Phytopathology 89:761-769.

16. Pannatier, Y. 1996. Variowin: Software for Spatial Data Analysis in 2D. Springer-Verlag, New York.

17. Patterson, C. L., Grogan, R. G., and Campbell, R. N. 1986. Economically important diseases of lettuce. Plant Dis. 70:982-987.

18. Reynolds, K. M., and Madden, L. V. 1988. Analysis of epidemics using spatio-temporal autocorrelation. Phytopathology 78:240-246.

19. Russo, J. M., Liebhold, A. M., and Kelley, J. G. W. 1993. Mesoscale weather data as input to a gypsy moth phenology model. J. Econ. Entomol. 86:838-844.

20. Scherm, H., Koike, S. T., Laemmlen, F. F., and van Bruggen, A. H. C. 1995. Field evaluation of fungicide spray advisories against lettuce downy mildew (Bremia lactucae) based on measured or forecast morning leaf wetness. Plant Dis. 79:511-516.

21. Scherm, H., and van Bruggen, A. H. C. 1993. Response surface models for germination and infection of Bremia lactucae the fungus causing downy mildew of lettuce. Ecol. Model. 65:281-296.

22. Scherm, H., and van Bruggen, A. H. C. 1994. Weather variables associated with infection of lettuce by downy mildew (Bremia lactucae) in coastal California. Phytopathology 84:860-865.

23. Schettini, T. M., Legg, E. J., and Michelmore, R. W. 1991. Insensitivity to metalaxyl in California populations of Bremia lactucae and resistance of California lettuce cultivars to downy mildew. Phytopathology 81:64-70.
24. Schnathorst, W. C. 1962. Comparative ecology of downy and powdery mildews of lettuce. Phytopathology 52:41-46.

25. Stein, A., Kocks, C. G., Zadoks, J. C., Frinking, H. D., Ruissen, M. A., and Myers, D. E. 1994. A geostatistical analysis of the spatio-temporal development of downy mildew epidemics in cabbage. Phytopathology 84:1227-1239.

26. Su, H., van Bruggen, A. H. C., and Subbarao, K. V. 1998. Moving air and relative humidity affect sporulation of Bremia lactucae. (Abstr.) Phytopathology 88(suppl.):S86.

27. Taylor, L. R. 1961. Aggregation, variance and the mean. Nature 189:732-735.

28. van Bruggen, A. H. C., Pennings, G. G. H., Moore, C. L., Wu, B. M., Subbarao, K. V., Koike, S., Bell, A., and Scherm, H. 1996. Geostatistical analysis of lettuce downy mildew incidence in coastal California. (Abstr.) Phytopathology 86(suppl.):S4-S5.

29. Van der Plank, J. E. 1975. Principles of Plant Infection. Academic Press, New York.

30. Verhoeff, K. 1960. On the parasitism of Bremia lactucae Regel on lettuce. Tjdschr. Plantenziekten 66:133-203.

31. Wu, B. M., Subbarao, K. V., and van Bruggen, A. H. C. 1998. Effects of solar radiation on survival of Bremia lactucae sporangia on lettuce leaves. (Abstr.) Phytopathology 88(suppl):S99.

32. Wu, B. M., van Bruggen, A. H. C., Subbarao, K. V., and Pennings, G. G. H. 1999. Spatial analysis of lettuce downy mildew (Bremia lactucae) in the Salinas Valley using geostatistics and GIS. (Abstr.) Phytopathology 89(suppl.):S86.

33. Xiao, C. L., Hao, J. J., and Subbarao, K. V. 1997. Spatial patterns of microsclerotia of Verticillium dahliae in soil and Verticillium wilt of cauliflower. Phytopathology 87:325-331. 